\title{
Effects of Haloperidol and Atypical Neuroleptics on Psychomotor Performance and Driving Ability in Schizophrenic Patients
}

\author{
Results from an Experimental Study \\ Sabine Kagerer Catja Winter Hans-Jürgen Möller Michael Soyka \\ Psychiatric Hospital, University of Munich, Munich, Germany
}

Key Words

Psychomotor performance · Driving ability ·

Schizophrenia · Haloperidol · Atypical neuroleptics could be regarded as competent to drive. Among patients with atypical neuroleptics, 7 patients (24\%) passed all test parameters without major failures.

Copyright $@ 2003$ S. Karger AG, Basel

\begin{abstract}
The influence of antipsychotic treatment on the neuropsychological and psychomotor performance of schizophrenic patients is still a subject of investigation. The present study was designed to evaluate the effects of atypical neuroleptics in comparison with a conventional dopamine antagonist neuroleptic (haloperidol) on several dimensions of psychomotor performance (visual perception, attention, reaction time, and sensorimotor performance) considered to be of relevance in evaluating driving fitness. Psychomotor performance was assessed by means of the ART 90, a computerized Act and React Test which is generally used in diagnosis of psychomotor performance. The 49 participating patients were examined at discharge following psychopathological stabilisation; 20 received haloperidol, 29 received an atypical neuroleptic. Our findings demonstrate a remarkably reduced psychomotor performance in the haloperidoltreated group of schizophrenic patients compared with patients treated with atypical neuroleptics. Only $1(5 \%)$ subject passed all subtests without major failures and
\end{abstract}

\section{Introduction}

Cognitive dysfunction in schizophrenia is common and has already been described by Kraepelin [1]. It is a key symptom in schizophrenia and is seen early in the development of the disorder. It is initially mild, but often increases in severity in chronic patients. Impaired cognitive function in schizophrenia is recognized as a pervasive deficit, which is independent of positive symptoms and often persists after reduction of psychotic symptoms. It is not restricted to any subgroup of patients and is seen in variable intensity among almost all schizophrenic patients [2]. However, it is difficult to distinguish syndromerelated dysfunction from cognitive impairment resulting from the side-effects of antipsychotic medications. Clinical data suggest that treatment with novel antipsychotic medications like risperidone, clozapine or amisulpride may have a positive effect on impaired cognition and psychomotor performance [3-6].

\begin{tabular}{ll}
\hline KARGER & ( ) 2003 S. Karger AG, Basel \\
0302-282X/03/0474-0212\$19.50/0 \\
$\begin{array}{l}\text { Fax +41613061234 } \\
\begin{array}{l}\text { E-Mail karger@karger.ch } \\
\text { www.karger.com }\end{array}\end{array}$ & $\begin{array}{l}\text { Accessible online at: } \\
\text { www.karger.com/nps }\end{array}$
\end{tabular}

Dipl. Psych. Sabine Kagerer, PhD

Psychiatric Hospital, Station C4, University of Munich

Nussbaumstrasse 7, DE-80336 Munich (Germany)

Tel. +49 8951605741, Fax +49 8951605748

E-Mail Sabine.Kagerer@psy.med.uni-muenchen.de 
The present study was designed to compare schizophrenic patients receiving an atypical neuroleptic with patients receiving a conventional dopamine antagonist neuroleptic (haloperidol) in relation to psychomotor performance. We used several psychomotor tests developed by the Austrian road safety board for the examination of car, bus, and taxi drivers in accordance with German guidelines for road and traffic safety [7]. However, driving ability is not only a matter of psychomotor performance. An individual's driving experience, coping strategies for deficits and compliance, which are not a subject of this study, must also be considered. Improvement in cognitive functioning leads to improved skills in social problem-solving, improved psychosocial skills and improved quality of life [8]. Driving fitness can be regarded as an important factor of social functioning and may be of importance for compliance with treatment.

There are few studies of schizophrenic patients which investigate the influence of antipsychotic medication on neuropsychological and psychomotor performance, especially on driving ability. Laux [9] and Grabe et al. [10] found that only $10 \%$ of neuroleptic-treated patients showed no impairment in fitness to drive during the last 2 weeks of their hospitalisation. The findings of Grabe et al. [10] indicate that clozapine-treated patients compared with patients treated with different classic neuroleptics performed better on a test measuring resistance to stress and the capacity to integrate information. However, only $10 \%$ of the patients in each group successfully passed every test in the test battery.

\section{Subjects and Methods}

We conducted a naturalistic, non-randomised, clinical study at the Psychiatric Hospital of the University of Munich, Munich, Germany, with 49 (28 male, 21 female) patients who met the ICD-10 and DSM-IV criteria for schizophrenia or a schizoaffective disorder. Study patients were clinically stabilized, had a steady state of neuroleptic medication and were ready for discharge. Of the 29 patients (15 male, 14 female) treated with atypical neuroleptics, 5 received clozapine, 4 received amisupride, 7 received riperidone, 8 received quetiapine, 4 received olanzapine and 1 received ziprasidone, all in different dosages. The 20 patients (13 male, 7 female $)$ treated with haloperidol received a dosage of 4-30 mg/day. Although a monotherapy was favoured, 7 received an additional medication when clinically indicated. There was no significant difference in age, sex, education and Brief Psychiatric Rating Scale (BPRS) scores between the haloperidol-treated group and the group treated with atypical neuroleptics. Patients were excluded if they had a disabling physical disorder, organic brain disorder, acute substance abuse, or any serious concurrent medical condition. There was no evidence of extrapyramidal-motoric symptoms in any of the study patients. All patients had either a valid driver's licence or intended to obtain one within the next few months. All subjects participated voluntarily in the study and gave their informed consent. A description of the sample is presented in table 1 .

Relevant psychomotor skills for driving fitness where assessed by the Act and React Test system (ART 90), a standardized and computerized test unit developed by the Austrian road safety board (Kuratorium für Verkehrssicherheit, Vienna, Austria). The reliability and validity of this test battery have been confirmed in large samples of both community and clinical subjects. In several driving experiments, the tests have been found to predict driving performance under different traffic situations $[11,12]$. The computerized tests of the ART system are often used in the evaluation of psychomotor performance in psychological examinations.

Tests measuring peripheral vision, divided attention, sensorimotor function, reaction time, stress resistance and the capacity to integrate information were used to assess psychomotor performance in relation to driving fitness. These tasks were selected as they are part of the driving examinations in Germany and had been used in previous studies investigating driving fitness $[10,13]$.

\section{Peripheral Vision Test with Tracking Task}

The Peripheral Vision Test (PVT) with tracking task assesses peripheral visual perception, divided attention, sensorimotor performance and reaction time. The subject is required to react to light patterns which randomly move from the left or right periphery into his/her visual field while performing a tracking test that is displayed in front of him/her.

\section{Tachistoscope Test}

The Tachistoscope Test (TT15) was designed to measure the ability to quickly extract relevant information from typical traffic situations presented for $0.75 \mathrm{~s}$. The subject has to answer 3 multiplechoice questions for each slide.

\section{Reactive Stress Tolerance Test}

The Reactive Stress Tolerance Test (RST3) requires a high level of concentration to visual and acoustic stimuli and tolerance to high stress in order to integrate information and to be able to react to each stimulus in the defined way. The subject is asked to press buttons, bars and pedals corresponding to presented colours, tones and light stimuli. The RST 3 has 3 test phases with different presentation rates, i.e. phase 1: $38 \mathrm{signs} / \mathrm{min}$; phase 2: $63 \mathrm{signs} / \mathrm{min}$, and phase $3: 56$ signs/min. The results of phase 2 with the highest speed of the presented stimuli are used as an indicator of stress resistance and the capacity to integrate information.

\section{Attention Test}

The attention test (Q1) examines attention under a monotonous condition. The subject has to identify as 'different' or 'identical' 4 figures that are presented constantly in 4 displays with another figure in a fifth display. The test is time dependent.

The computerized test system evaluates the subjects' test performance in comparison with the population norms. The test administrator is able to determine if the performance of the tested person exceeds the defined threshold of $15 \%$, i.e., $1 \mathrm{SD}$ below the mean of the population norm. As there are no general standards for successful test performance, the test administrator decides whether the person is able to compensate for deficits in individual test performance; however, test performance deficits are not cumulative 
Table 1. Sample characteristics of the two groups

\begin{tabular}{lll}
\hline & $\begin{array}{l}\text { Atypical neuroleptics } \\
(\mathrm{n}=29)\end{array}$ & $\begin{array}{l}\text { Haloperidol } \\
(\mathrm{n}=20)\end{array}$ \\
\hline Mean age, years & $30.3(19-49)$ & $33.1(19-49)$ \\
Sex (M/F) & $15 / 14$ & $13 / 7$ \\
Mean medication dosage, mg & 4 patients: amisulpride 625 (400-1,000) & $7.3(4-30)$ \\
& 5 patients: clozapine 285 $(125-450)$ & \\
& 8 patients: quetiapine $744(200-1,200)$ & \\
& 7 patients: risperidone 5 $(3-10)$ & \\
& 4 patients: olanzapine 21.25 $(20-25)$ & 5.7 \\
Hospitalization, weeks & 1 patient: ziprasidone 80 & 12 \\
ICD-10 diagnosis & 9.7 & 2 \\
F 20.0 & 21 & 2 \\
F 20.1 & 4 & 4 \\
F 20.2 & 1 & 0 \\
F 23.2 & 1 & 27.0 \\
F 25.1 & 2 & 3.4 \\
Mean BPRS scores at examination & 26.3 & \\
Mean level of education (9-18 years) ${ }^{1}$ & 3.3 & \\
\hline
\end{tabular}

Figures in parentheses indicate ranges.

1 On a scale from 1 to 5 .

across the battery. The more test scores fall 1 SD below the mean, the less likely the person is able to compensate deficits. If a person's score falls below the threshold on more than 4 test parameters, he/ she was rated as unable to compensate for his/her deficits and unfit to drive.

Statistical data analysis was performed using SPSS (Statistical Package for Social Science, Version 11.0, Chicago, SPSS Inc., 2002). Non-parametric tests were conducted, since the test scores were not normally distributed. The Mann-Whitney U test was used to determine between-group differences, and Spearman correlations were computed to determine the relation between neurocognitive test results and education, duration of stay at the hospital, and BPRS scores. As an index of effect size, the mean of between-group differences was used.

\section{Results}

First, the overall psychomotor performance of subjects was examined to determine their driving ability in relation to the German regulations of road safety. For each of the 4 tests, the subjects' performance was indicated by multiple scores. The raw score data were compared with the performance of large samples of normal controls. A test is considered as 'passed' if the patient exceeds the threshold of $15 \%$ with respect to each unit of the test $(16 \%$

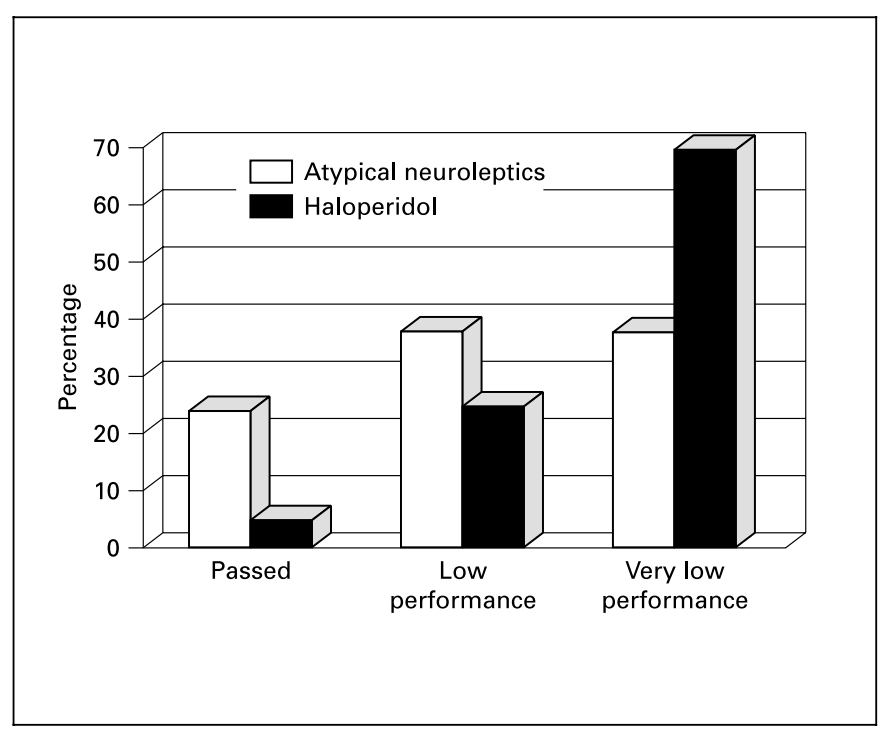

Fig. 1. Psychomotor test performance of patients treated with atypical neuroleptics vs. haloperidol. Passed = All tests; low performance $=$ failed $1-4$ test parameters; very low performance $=$ failed $>4$ test parameters. 
Table 2. Test performance of both groups

\begin{tabular}{|c|c|c|c|c|c|}
\hline Test & $\begin{array}{l}\text { Atypical } \\
\text { neuroleptics, } \\
\text { mean } \pm S D \\
(n=29)\end{array}$ & $\begin{array}{l}\text { Haloperidol } \\
\text { mean } \pm \text { SD } \\
(\mathrm{n}=20)\end{array}$ & $\begin{array}{l}\text { Effect } \\
\text { size }\end{array}$ & $\mathrm{z}$ & $\mathrm{p}$ \\
\hline \multicolumn{6}{|l|}{ PVT } \\
\hline Reaction time, total s & $1.8 \pm 0.8$ & $1.8 \pm 0.9$ & 0 & -0.432 & 0.666 \\
\hline Tracking performance, mean deviation in total & $4.1 \pm 2.0$ & $4.9 \pm 1.8$ & 0.8 & -2.238 & $0.025^{*}$ \\
\hline \multicolumn{6}{|l|}{ TT15 } \\
\hline Correct answers & $29.1 \pm 4.9$ & $30.1 \pm 4.5$ & 1 & -0.384 & 0.701 \\
\hline Mean reaction time, min & $4.4 \pm 1.6$ & $3.4 \pm 0.8$ & 1 & -2.712 & $0.007 *$ \\
\hline \multicolumn{6}{|l|}{ Q1 } \\
\hline Completed trials & $407.0 \pm 106.7$ & $381.7 \pm 85.5$ & 25.3 & -0.706 & 0.480 \\
\hline Incorrect responses, $\%$ & $4.3 \pm 4.9$ & $4.5 \pm 4.5$ & 0.2 & -0.591 & 0.591 \\
\hline \multicolumn{6}{|l|}{ RST3 (Phase 1) } \\
\hline Correct responses & $165.5 \pm 20.0$ & $156.3 \pm 28.5$ & 9.2 & -1.570 & 0.116 \\
\hline Correct answers on time & $152.2 \pm 32.1$ & $138.6 \pm 34.9$ & 13.6 & -1.993 & $0.046^{*}$ \\
\hline Delayed responses & $13.4 \pm 14.6$ & $17.8 \pm 11.8$ & 4.4 & -1.786 & 0.074 \\
\hline Delayed compared with correct responses, $\%$ & $9.1 \pm 11.4$ & $12.4 \pm 9.3$ & 3.3 & -1.904 & 0.057 \\
\hline Omissions & $10.2 \pm 15.0$ & $19.8 \pm 25.8$ & 9.6 & -1.654 & 0.098 \\
\hline Incorrect responses & $4.2 \pm 6.5$ & $3.9 \pm 4.2$ & 0.3 & -0.792 & 0.428 \\
\hline Incorrect compared with total responses, $\%$ & $5.3 \pm 6.4$ & $7.7 \pm 10.3$ & 2.4 & -1.358 & 0.174 \\
\hline Multiple responses & $4.9 \pm 5.8$ & $9.6 \pm 19.3$ & 4.7 & -0.861 & 0.389 \\
\hline \multicolumn{6}{|l|}{ RST3 (Phase 2) } \\
\hline Correct responses & $134.2 \pm 37.6$ & $106.8 \pm 26.2$ & 27.4 & -2.504 & $0.012 *$ \\
\hline Correct answers on time & $70.7 \pm 50.3$ & $39.0 \pm 43.6$ & 31.7 & -2.056 & $0.040^{*}$ \\
\hline Delayed responses & $62.0 \pm 23.9$ & $70.33 \pm 23.8$ & 8.3 & -1.147 & 0.251 \\
\hline Delayed compared with correct responses, $\%$ & $53.1 \pm 26.4$ & $69.2 \pm 24.7$ & 16.1 & -1.894 & 0.058 \\
\hline Omissions & $39.8 \pm 32.7$ & $60.7 \pm 26.7$ & 20.9 & -1.870 & 0.061 \\
\hline Incorrect responses & $6.3 \pm 6.8$ & $9.9 \pm 9.4$ & 3.6 & -1.552 & 0.121 \\
\hline Incorrect compared with total responses, $\%$ & $10.8 \pm 10.3$ & $15.0 \pm 12.2$ & 4.2 & -1.387 & 0.166 \\
\hline Multiple responses & $8.2 \pm 8.0$ & $9.4 \pm 11.0$ & 1.2 & -0.025 & 0.980 \\
\hline \multicolumn{6}{|l|}{ RST3 (Phase 3) } \\
\hline Correct responses & $148.4 \pm 32.9$ & $131.3 \pm 30.4$ & 17.1 & -1.784 & 0.074 \\
\hline Correct answers on time & $102.3 \pm 53.3$ & $70.6 \pm 40.6$ & 31.7 & -1.820 & 0.069 \\
\hline Delayed responses & $46.0 \pm 27.2$ & $60.9 \pm 28.4$ & 14.9 & -1.709 & 0.087 \\
\hline Delayed compared with correct responses, $\%$ & $35.7 \pm 26.0$ & $48.4 \pm 21.9$ & 12.7 & -1.721 & 0.085 \\
\hline Omissions & $26.2 \pm 28.2$ & $40.7 \pm 26.4$ & 14.5 & -1.883 & 0.060 \\
\hline Incorrect responses & $5.4 \pm 6.8$ & $7.7 \pm 6.7$ & 2.3 & -1.595 & 0.111 \\
\hline Incorrect compared with total responses, $\%$ & $8.4 \pm 10.2$ & $12.3 \pm 12.3$ & 3.9 & -1.510 & 0.131 \\
\hline Multiple responses & $7.2 \pm 9.8$ & $10.7 \pm 15.0$ & 7.2 & 1.092 & 0.275 \\
\hline
\end{tabular}

reflects $1 \mathrm{SD}$ below the mean score of normal controls). Adequate driving ability is indicated if the subject exceeds the threshold of $15 \%$ in each unit of the 4 tests.

Among patients treated with atypical neuroleptics, 7 persons out of $25(24 \%)$ passed each unit of the 4 tests which means exceeding the $15 \%$ guideline (fig. 1) regarding fitness to drive. Of these 7 patients, 2 received cloza- pine, 1 received amisulpride (along with biperiden and benzodiazepine), 1 received olanzapine, 1 received risperidone (along with biperiden) and 2 received quetiapine. Of the haloperidol-treated patients, only 1 person $(5 \%)$ passed all tests without any failures.

According to the German driving examination guidelines, low driver performance on some test parameters is 
allowed, if the results on other tests are satisfactory; an accumulation of test deficits across the examination is excluded. In these cases, pass/fail is determined by the test administrator. Eleven patients (38\%) treated with atypical neuroleptics showed a low performance on 1-4 test scores, while 5 patients $(25 \%)$ in the haloperidol-treated group failed the threshold of $15 \%$ on 1-4 test scores. For these patients, further examinations were recommended.

Poor test performance on more than 4 test parameters (i.e., very low performance) was found for 14 patients $(70 \%)$ treated with haloperidol and 11 patients (38\%) treated with atypicals. These patients, in our opinion, were not able to compensate for their psychomotor deficits and were classified as unfit for driving. Three of the haloperidol-treated patients were not able to complete all of the tests and testing was stopped. In the statistical analysis comparing the two groups (table 2), their data were considered as 'missing'. For the analysis, they were rated as 'failed' on the relevant test parameters. One person misunderstood the test instructions of 1 test, while 3 subjects refused to complete all 4 tests. A tendency of an association between grouping variables (haloperidol vs. atypicals) and classification ('passed', 'low performance', 'very low performance') was observed (Pearson's $\chi^{2}$ test 5.647, d.f. $=2, p=0.058)$.

Next, the two groups were compared without using a threshold definition considering each test score of the 4 tests (table 2). On the PVT, a significant between-group difference was found on 1 item of the test. Patients treated with the atypical neuroleptics showed a significantly better psychomotor performance on the tracking task; no between-group differences were found on reaction time in this test. On the TT15, the haloperidol-treated group showed a significantly shorter reaction time. No differences were found in the number of correct response items. On the Q1, no significant between-group differences were found. On the RST3, a test measuring stress resistance and the capacity to integrate information, the patients treated with atypical neuroleptics showed a better performance on all dimensions. In phase 1 of the test, patients treated with atypical neuroleptics performed significantly better on time responses. In phase 2, the 'highest stress level', patients treated with atypical neuroleptics provided significantly more correct responses and more correct responses in time allowed, a tendency of a less percentage of delayed responses $(p=0.058)$ and less omissions $(p=0.061)$ than the haloperidol-treated subjects. In phase 3 of the RST3, a tendency of a better performance of the group treated with atypical neuroleptics was seen across all dimensions. They provided more correct an- swers $(p=0.074)$, more correct answers in time allowed $(p=0.069)$, less delayed responses $(p=0.085)$ and less omissions $(\mathrm{p}=0.060)$ than the haloperidol-treated patients.

Furthermore, a correlation analysis was conducted to examine the relationship between psychomotor test performance and age, BPRS score, educational level, and the duration of stay at the hospital.

No association was found between psychomotor test results and education or duration of stay at the hospital. However, there was a significant, but low correlation between age and correct answers in phase 2 of the RST3 $(\rho=-0.325)$, correct answers on time in the second ( $\rho=$ $-0.414)$ and third phase of the RST3 $(\rho=-0.351)$, and delayed responses in phase $2(\rho=0.379)$ and phase $3(\rho=$ 0.398). Similarly, a significant, but low correlation between age and the tracking performance on the PVT test $(\rho=0.397)$ was observed. Younger patients showed a better test performance than older patients did. The BPRS score was significantly correlated with only 2 items of the RST3 (number of omissions in phase $1, \rho=0.307$ and percentage of omissions in phase $1, \rho=0.307$ ).

\section{Discussion}

Functional status including psychomotor skills and driving ability is of great importance for the rehabilitation of schizophrenic patients. Palmer et al. [14] reported that $43 \%$ of middle-aged and elderly out-patients with schizophrenia are currently drivers. The role of different neuroleptics in affecting neuropsychological abilities is of great relevance in this respect, a relationship which only few studies have examined to date.

Schizophrenic patients treated with different atypical neuroleptics were compared with those treated with haloperidol in relation to their psychomotor functioning, including driving fitness. Patients were examined at discharge following neuroleptic treatment and psychopathological stabilisation - a clinical situation in which the question of driving ability is of relevance.

The main result of our study is that the group of haloperidol-treated patients showed considerable psychomotor impairment compared with patients who received an atypical neuroleptic medication.

The significantly better results in some parameters of the RST3 indicating a better stress tolerance among the patients treated with atypical neuroleptics support the findings of other published studies indicating a positive effect of atypical neuroleptics on cognition [13, 15-17]. 
Grabe et al. [10], also observed a better psychomotor test performance of clozapine-treated patients compared with patients treated with perazine, flupentixol, haloperidol, chlorprothixene and amisulpride on the RST3. However, they found no differences between both groups in terms of the number of individuals who passed all tests without failures. Similarly, Gallhofer et al. [4] found that risperidone and clozapine may have a positive effect on cognition compared with haloperidol in schizophrenic patients. Hagger et al. [18] and Buchanan et al. [19] reported a significant improvement in neuropsychological performance during clozapine treatment in schizophrenic patients. Purdon et al. [20] found that olanzapine produced a substantial gain in cognitive skills greater than that observed with risperidone or haloperidol. Sax et al. [21] reported a significant improvement during treatment with quetiapine in attentional functioning in patients with schizophrenia. However, Classen and Laux [22] did not find major differences in sensorimotor performance comparing schizophrenic patients treated with haloperidol, flupentixol and clozapine.

Since this study was conducted in a clinical setting, certain study limitations in relation to subject selection must be discussed. First, a certain selection of patients must be noted. Only patients with clear psychopathological improvement, free of relevant other medical disorders were able to participate. Since the entire experimental procedure lasted $90 \mathrm{~min}$, on average, severely disturbed patients had to be excluded. The ability to drive must be excluded as part of their clinical condition. Second, the study followed a naturalistic approach. The sample received different types and dosages of medication, and some patients received additional medications as clinically indicated. Group differences in duration of illness, individual motivation, in psychopathology and additional symptoms (like mood or sleep disturbance) may be present.

According to our findings, even after selection of comparatively well-stabilized patients, severe impairment of psychomotor performance can be noticed. A careful evaluation of the driving abilities of schizophrenic patients is recommended, as there can be considerable individual differences between patients. Even though driving ability was judged by using the ART-90, a very reliable and objective method, a linear association between a person's test results and driving ability is not absolutely warranted. Other important variables such as driving experience, personality traits, duration and course of the illness (which were not part of our investigation) are of relevance. In addition, it must be emphasized that patients should be informed about the danger of the combination of antipsychotic medication and alcohol. Vollrath and Krüger [23] reported an exponentially increased risk of an accident if psychotropic substances like benzodiazepines or cannabis are combined with alcohol.

To verify our findings, additional prospective, randomised studies with larger samples should be conducted. Medication, dosing issues, the possible influences of other medications, psychopathological symptoms and the duration of illness should be considered to address the important issue of medication effects on neuropsychological functioning among schizophrenic patients.

\section{Acknowledgement}

The expertise of Dr. M. Wiseman (Leipnitz Rechenzentrum) for statistical methods applied is kindly acknowledged.

\section{References}

1 Kraepelin E: Dementia Praecox and Paraphrenia. Edinburgh, Livingstone, 1919

2 Goldberg TE, Ragland JD, Torrey EF, et al: Neuropsychological assessment of monozygotic twins discordant for schizophrenia. Arch Gen Psychiatry 1990;47:1066-1072.

3 Green MF, Marshall BD Jr, Wirshing WC, Ames D, Marder SR, McGurk S, Kern RS, Mintz J: Does risperidone improve verbal working memory in treatment-resistent schizophrenia? Am J Psychiatry 1997;154:799-804.

4 Gallhofer B, Bauer U, Lis S, Krieger S, Gruppe $\mathrm{H}$ : Cognitive dysfunction in schizophrenia: Comparison of treatment with atypical antipsychotic agents and conventional neuroleptic drugs. Eur Neuropsychopharmacol 1996; 6(suppl 2):S13-S20.
5 Ramaekers J, Louwerens J, Muntjewerff N, Milius H, DeBie A, Rosenzweig P, Patat A, O'Hanlon JF: Psychomotor, cognitive, extrapyramidal, and affective function of healthy volunteers during treatment with an atypical (amisulpride) and a classic (haloperidol) antipsychotic. J Clin Psychopharmacol 1999;19: 209-221.

6 Harvey P, Keefe R: Studies of cognitive change in patients with schizophrenia following novel antipsychotic treatment. Am J Psychiatry 2001;158:176-184.
7 Lewrenz H: Begutachtungs-Leitlinien zur Kraftfahrereignung des Gemeinsamen Beirats für Verkehrsmedizin beim Bundesministerium für Verkehr, Bau und Wohnungswesen beim Bundesministerium für Gesundheit. Berichte der Bundesanstalt für Strassenwesen. Bergisch Gladbach, 2000, vol M115.

8 Green MF: What are the functional consequences of neurocognitive deficits in schizophrenia? Am J Psychiatry 1996;153:321-330.

9 Laux G: Zum Problem der Fahrtauglichkeit schizophrener Patienten unter Neuroleptikatherapie; in Möller HJ, Müller N (eds): Schizophrenie - moderne Konzepte zu Diagnostik, Pathogenese und Therapie. Wien, Springer, 1998. 
10 Grabe HJ, Wolf T, Grätz S, Laux G: The influence of clozapine and typical neuroleptics on information processing of the central nervous system under clinical conditions in schizophrenic disorders: Implications for fitness to drive. Neuropsychobiology 1999;40: 196-201.

11 Risser R, Schmidt L, Brandstätter C, Bukasa B, Wenninger U: Verkehrspsychologische Testverfahren und Kriterien des Fahrverhaltens. Wien, Verkehrspsychologisches Institut des Kuratoriums für Verkehrssicherheit, 1993.

12 Bukasa B, Wenninger U, Brandstätter C: Validierung verkehrspsychologischer Testverfahren. Kleine Fachbuchreihe des Kuratoriums für Verkehrssicherheit. Wien, Literas, 1990.

13 Soyka M, Dittert S, Schäfer M, Gartenmaier A, Laux G, Winter C, Möller HJ: Psychomotor performance under neuroleptic treatment in schizophrenia. A comparative study of haloperidol and risperidone. Z Neuropsychol 2001; 12:49-53.
14 Palmer BW, Heaton RK, Gladsjo JA, Evans JD, Patterson TL, Golshan S, Jeste DV: Heterogeneity in functional status among older outpatients with schizophrenia: Employment history, living situation, and driving. Schizophr Res 2002;55:205-215.

15 Melzer HY, McGurk SR: The effects of clozapine, risperidone and olanzapine on cognitive function in schizophrenia. Schizophr Bull 1999;25:233-255.

16 Stip E, Lussier I: The effect of risperidone on cognition in patients with schizophrenia. Can J Psychiatry 1996;41(suppl 2):35-40.

17 Kern RS, Green MF, Marshall BD Jr, Wirshing WC, Wirshing D, Mc Gurk S. Marder SR, Mintz J: Risperidone vs haloperidol on reaction time, manual dexterity and motor learning in treatment-resistant schizophrenia patients. Biol Psychiatry 1998;44:726-732.

18 Hagger C, Buckley P, Kenny JT, Friedman L, Ubogy D, Meltzer HY: Improvement in cognitive function and psychotic symptoms in treatment-refractory schizophrenic patients. Biol Psychiatry 1993;34:702-712.
19 Buchanan RW, Holstein C, Breier A: The comparative efficacy and long-term effect of clozapine treatment on neuropsychological test performance. Biol Psychiatry 1994;36:717-725.

20 Purdon SE, Jones B, Stip E, Labelle A, Addington D, David S, Breier A, Tollefson G: Neuropsychological change in early phase schizophrenia during 12 months of treatment with olanzapine, risperidone, or haloperidol. Arch Gen Psychiatry 2000;57:249-258.

21 Sax KW, Strakowski SM, Keck, PR: Attentional improvement following quetiapine fumarate treatment in schizophrenia. Schizophr Res 1998;33:151-155

22 Classen W, Laux G: Sensorimotor and cognitive performance of schizophrenic inpatients treated with haloperidol, flupenthixol or clozapine. Pharmacopsychiatry 1988;21:295-297.

23 Vollrath M, Krüger HP: Gefährdung der Verkehrssicherheit durch Alkohol, Drogen und Benzodiazepine - ein Überblick. Suchtmed 2002;4:175-183. 